\title{
Influence of reuse and cervical preflaring on the fracture strength of reciprocating instruments
}

\author{
Claudio Maniglia-Ferreira ${ }^{1}$, Fabio de Almeida Gomes ${ }^{1}$, Tatyana Ximenes ${ }^{1}$, \\ Murilo Alves Teixeira Neto ${ }^{1}$, Thiane Elys Arruda ${ }^{1}$, Giovani Gonçalves Ribamar ${ }^{2}$, \\ Luis Flávio Gaspar Herculano²
}

Correspondence: Dr. Claudio Maniglia-Ferreira

Email: maniglia@unifor.br

${ }^{1}$ Department of Endodontics, Course of Dentistry, University of Fortaleza, Fortaleza, CE, Brazil, 2Department of Metallurgical and Materials Engineering, Faculty of Chemical Engineering, Federal University of Ceará, Fortaleza, CE, Brazil

\section{ABSTRACT}

Objective: This study sought to assess the influence of cervical preflaring and reuse after resterilization, on fracture strength and plastic deformation and/or surface cracking in reciprocating nickel-titanium [NiTi] endodontic instruments after root canal instrumentation of extracted human teeth. Materials and Methods: Forty engine-driven reciprocating NiTi instruments (20 Reciproc ${ }^{\circledR}$ [RC], VDW; 20 WaveOne $^{\circledR}$ [WO], Dentsply) were used in root canal instrumentation of extracted human molars. A total of 485 human upper molars with similar anatomical features were selected and randomly distributed across four groups according to the instrumentation procedures performed (G1 and G3: RC; G2 and G4: WO). Reciprocating instruments were used as per manufacturer instructions. In groups G3 and G4, cervical preflaring was performed prior to instrumentation. After each use of each instrument, sterilization was repeated and scanning electron microscope (SEM) images were obtained to check for plastic deformations and/or cracks on instrument surfaces. Each instrument was used repeatedly until fracture occurred. Results: Regardless of flaring, RC files exhibited greater fracture strength than WO instruments $(P<0.01)$ with and without preflaring. Cervical preflaring significantly reduced the risk of instrument fracture $(P<0.01)$. No plastic deformations were observed before fracturing. However, cracks were found on WO instruments shortly after their first use. RC and WO instruments resisted fracturing after autoclave sterilization. Conclusions: Cervical preflaring allowed a significant increase in the number of times RC and WO files could be reused safely.

Key words: Dental instruments, endodontics, Reciproc, root canal preparation, WaveOne

\section{INTRODUCTION}

The advent of rotary nickel-titanium (NiTi) instrumentation has brought significant progress to root canal preparation in terms of preserving native root canal morphology and preventing apical transportation..${ }^{[1,2]}$ However, separation of instruments during continuous rotary motion is the most common accident in clinical practice. ${ }^{[3]}$

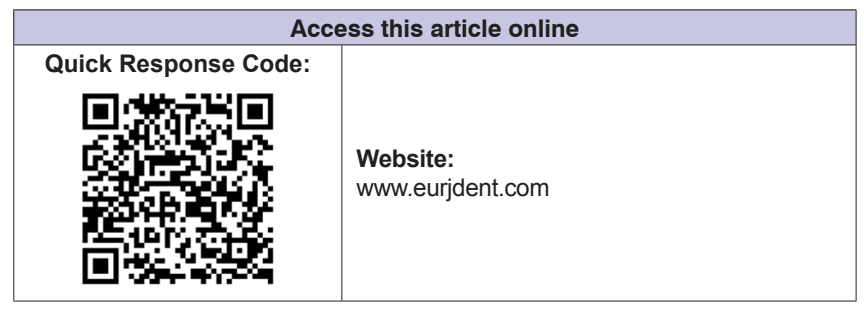

NiTi instruments may exhibit premature fatigue failure, ${ }^{[4]}$ thus reducing the life of the instrument or torsional stress failure, which is the result of file binding to the canal walls. ${ }^{[5]}$ Therefore, rotary instrumentation requires manual or mechanical cervical preflaring to mitigate fracture risk. ${ }^{[6,7]}$

This is an open access article distributed under the terms of the Creative Commons Attribution-NonCommercial-ShareAlike 3.0 License, which allows others to remix, tweak, and build upon the work non-commercially, as long as the author is credited and the new creations are licensed under the identical terms.

For reprints contact: reprints@medknow.com

How to cite this article: Maniglia-Ferreira C, de Almeida Gomes F, Ximenes T, Neto MA, Arruda TE, Ribamar GG, et al. Influence of reuse and cervical preflaring on the fracture strength of reciprocating instruments. Eur J Dent 2017;11:41-7.

DOI: 10.4103/ejd.ejd_272_16 
In 2008, Yared ${ }^{[8]}$ used a single rotating instrument (ProTaper) in reciprocating motion for canal preparation and shaping and demonstrated that the technique provides greater speed, good cost-benefit ratio, and reduced fracture rates. A new approach to root canal preparation was introduced in 2010 with the Reciproc (RC) system (VDW, Munich, Germany) and later by the WaveOne (WO) system (Dentsply Maillefer, Ballaigues, Switzerland). Both use a single NiTi M-Wire alloy instrument driven by reciprocating motion, whereby the instrument cuts the dentin wall of the root canal during the counterclockwise rotation, when taper lock is imminent. The following clockwise motion then disengages the instrument from dentin, reducing the incidence of separation. ${ }^{[1,9]}$

According to manufacturer recommendations, a glidepath must be prepared using small (\#10 and \#15) rotary or hand files, but cervical preflaring is unnecessary. ${ }^{[10]}$ Within the context of widespread use of reciprocating systems, the present study assessed the influence of multiple reuse (after resterilization) and cervical preflaring on fracture strength, plastic deformation, and/or surface cracking in $\mathrm{RC}$ and WO reciprocating instruments after root canal instrumentation in extracted human teeth. The null hypothesis was that both instrument systems would be equally fracture resistant when driven by reciprocating motion, with and without cervical preflaring.

\section{MATERIALS AND METHODS}

\section{Ethical aspects and sample selection}

The present study was approved by the local research ethics committee (CAAE: 13831213.4 .0000 .5052$)$. The sample comprised extracted human upper molars (length 18-22 mm) with fully formed roots, constricted root canals, and root curvature $\leq 35^{\circ}$. For selection purposes, teeth were identified and imaged by conventional radiography and cone beam computed tomography. Only teeth in which the entire root canal system could be visualized were included in the sample for experimental group allocation. All root canals of all selected teeth were included in the study. Teeth with root curvature $>35^{\circ}$, partially or completely calcified canals, or excessively wide canals were excluded from the study. After application of the selection criteria, 550 teeth were selected from a set of 1153 extracted human molars. Of the 550 selected teeth, 485 were used in the study. Figure 1 provides a schematic illustration of the study methods.

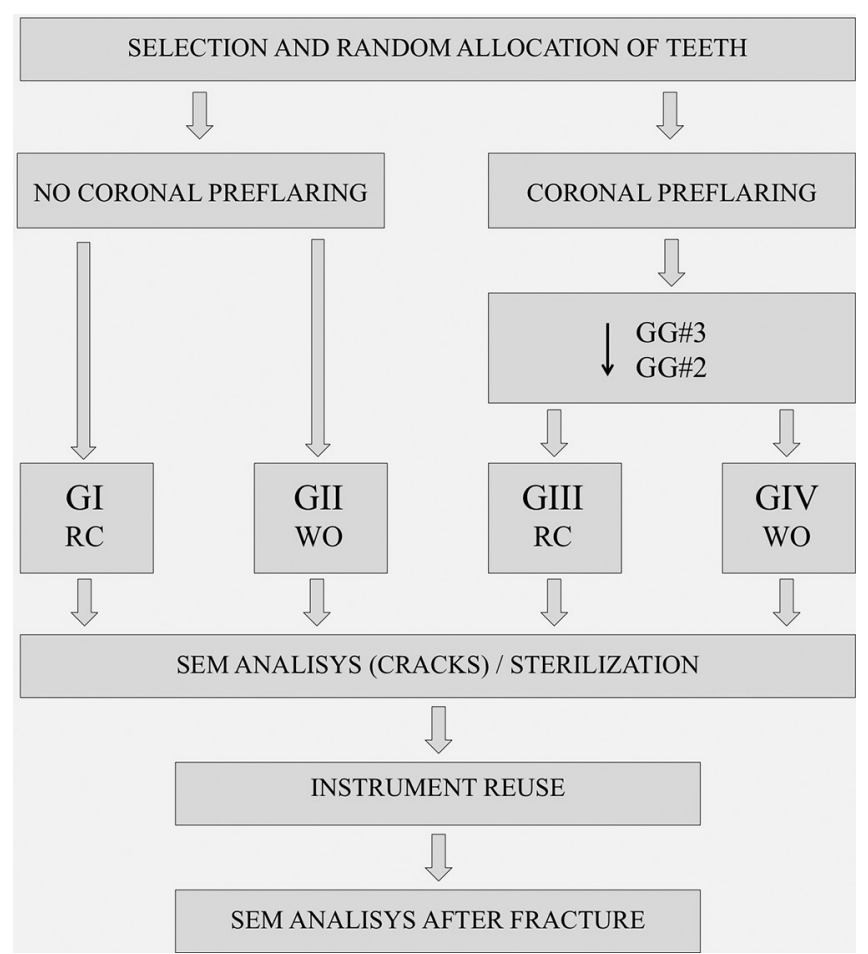

Figure 1: Study flowchart

\section{Preparation of specimens}

In all selected teeth, endodontic access was established using high-speed diamond burs. Canal orifices were located with an endodontic explorer and special files under $\times 32$ magnification (MC-M1233 operating microscope, DFV Com. and Ind. Ltda, Valença, RJ, Brazil), and teeth were then randomly allocated across the different study groups. The presence of a fourth canal was identified in $41.2 \%$ of the teeth used in the sample $(n=200)$. These teeth were distributed equally across the study groups.

\section{Division of experimental groups}

Forty $25-\mathrm{mm}$ reciprocating instruments were used in this study: 20 Reciproc $^{\circledR} \mathrm{R} 25$, tip size 25, 0.08 variable taper (RC) (VDW GmbH, Munich, Germany) and 20 WaveOne $^{\circledR}$ Primary, tip size 25, 0.08 variable taper (WO) (Dentsply-Maillefer, Ballaigues, Switzerland), all powered by a Silver Reciproc Motor and Sirona ENDO 6:1 contra-angle handpiece (VDW GmbH, Munich, Germany). Instruments were driven according to the preset programs defined by the motor manufacturer. RC files were driven by the RC ALL program and WO files by the WO ALL program.

Four study groups ( $n=10$ each) were defined, according to root canal instrumentation procedure:

- G1: RC;

- G2: Cervical preflaring with Gates-Glidden drills 
(\#3 and \#2) (Dentsply-Maillefer, Ballaigues, Switzerland) + RC;

- G3: WO;

- G4: Cervical preflaring with Gates-Glidden drills (\#3 and \#2) + WO.

\section{Root canal preparation}

Instruments were used in alternating order. Procedures were performed by a single operator, who followed the manufacturer-issued instructions for each instrument. After coronal access, teeth were irrigated with $5 \mathrm{~mL}$ sodium hypochlorite $(\mathrm{NaOCl}) 2.5 \%$ (Biodinâmica Química e Farmacêutica Ltda, Ibiporã, PR, Brazil) and explored with hand files as described elsewhere. The root canals were irrigated with $5 \mathrm{~mL} 2.5 \% \mathrm{NaOCl}$ after each instrumentation.

The root canal systems of all teeth were evacuated with a \#10 K-file, which was used to identify patency. Working length determination was performed under operating microscope magnification (MC-M1233, DFV Com. \& Ind. Ltda, Valença, RJ, Brazil), $1 \mathrm{~mm}$ short of the apex. In all teeth, glidepaths were prepared with a \#13/0.02 mm/mm PathFile (Dentsply-Maillefer, Ballaigues, Switzerland), which enabled standardized canal preparation.

In Groups G1 and G3, instrumentation was performed with a single file ( $R C$ and $W O$, respectively) in reciprocating motion, advancing into each root third in 3-mm increments until the desired length was reached, as recommended by the manufacturers.

In Groups G2 and G4, instrumentation was preceded by cervical preflaring, performed using \#2 and \#3 Gates-Glidden drills (Dentsply-Maillefer, Ballaigues, Switzerland), in descending order, and driven by a Reciproc Silver motor programmed appropriately for these instruments. After this step, RC and WO instruments were used as in Groups G1 and G3. After each use, any dentin chip adhered to the instruments was removed with moist gauze dressings, and the root canals were irrigated again with $5 \mathrm{~mL}$ of $\mathrm{NaOCl}$ and recapitulated with a \#10 K-file to full length.

Once instrumentation of each tooth was complete, the instruments were decontaminated and cleaned in an ultrasonic unit, examined under the operating microscope for potential plastic deformation, and autoclaved for later reuse. This procedure was repeated for all instruments. To enable reuse after sterilization, the identification ring of each instrument was removed with a scalpel blade so as to allow reinsertion into the Sirona contra-angle handpiece. Each instrument was used repeatedly until fracture occurred, at which time the instrument was identified, and the number of uses until separation was recorded.

\section{Scanning electron microscopy}

The surfaces of all instruments were analyzed by scanning electron microscopy (SEM), performed with a DSM-940A system (Carl Zeiss, Jena, Germany), and checked for surface changes potentially caused by irrigant exposure and for cracks or plastic deformation caused by continued instrumentation. SEM images (magnification $\times 100, \times 250, \times 500$, and $\times 1000$ ) were obtained at three time points for each instrument: Before use [Figure 2]; after first use [Figure 3]; and after fracture [Figure 4].

\section{Statistical analysis}

Statistical procedures were performed with the Statistical Package for the Social Sciences (SPSS 17.0 for Windows, SPSS Inc., Chicago, USA). Because values were normally distributed across all groups, one-way analysis of variance was used for comparative purposes. The level of significance was set at $5 \%$.

\section{RESULTS}

Overall study results are shown in Table 1. RC files exhibited significantly greater fracture strength than WO files $(P<0.001)$, under equal conditions. Comparison of groups in which the same instruments

\begin{tabular}{|c|c|c|c|c|}
\hline Groups & $\begin{array}{c}\text { Teeth } \\
\text { (mean } \pm S D)\end{array}$ & Total & $\begin{array}{c}\text { Root canals } \\
\text { (mean } \pm S D)\end{array}$ & Total \\
\hline G1 (RC) & $10.9 \pm 1.20^{\mathrm{A}}$ & 109 & $37.1 \pm 3.9^{A}$ & 371 \\
\hline G2 (WO) & $6.2 \pm 1.03^{\mathrm{B}}$ & 62 & $21.2 \pm 3.4^{\mathrm{B}}$ & 212 \\
\hline $\mathrm{G} 3(\mathrm{CP}+\mathrm{RC})$ & $19.7 \pm 1.34^{\mathrm{C}}$ & 197 & $67.5 \pm 4.22^{\mathrm{C}}$ & 675 \\
\hline $\mathrm{G} 4(\mathrm{CP}+\mathrm{WO})$ & $11.7 \pm 1.25^{\mathrm{A}}$ & 117 & $39.9 \pm 3.67^{A}$ & 399 \\
\hline
\end{tabular}

Different letters indicate results with significant statistically differences. SD: Standard deviation, RC: Reciproc ${ }^{\circledast}$, WO: WaveOne ${ }^{\circledR}$, CP: Cervical preflaring

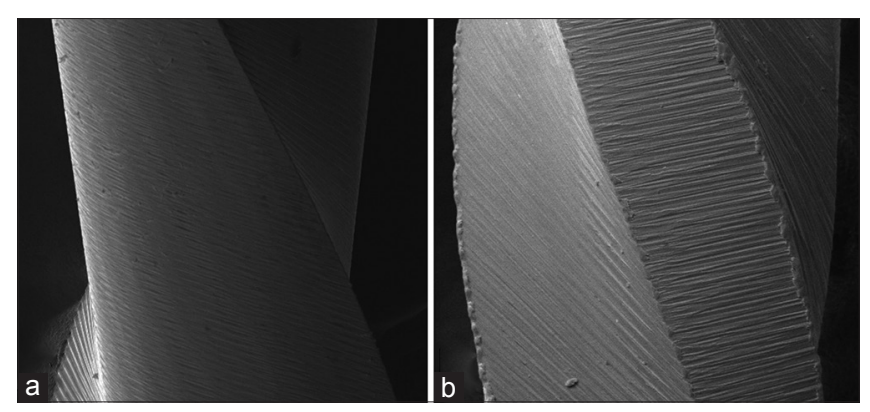

Figure 2: Scanning electron microscope images of $\operatorname{Reciproc}^{\circledR}$ (a) and WaveOne ${ }^{\circledR}(b)$ instruments before use 


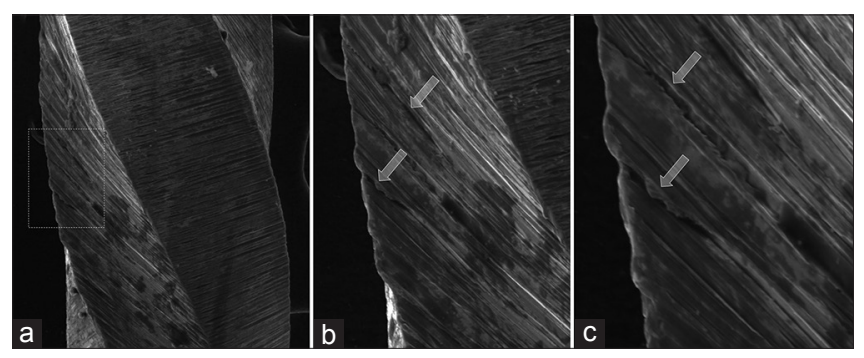

Figure 3: Surface images of WaveOne ${ }^{\circledR}$ instruments after the first use. Note the presence of surface cracks on the WaveOne ${ }^{\circledast}$ instrument (arrows) (scanning electron microscope images magnification: $\mathrm{a}-\times 250$; b - ×500; c $-\times 1000)$

were used revealed that cervical preflaring significantly increased the fracture strength $(P<0.01)$ of both instrument systems. On comparison between different instrument systems with and without preflaring, RC files exhibited the same fracture strength as WO files did after preflaring, providing further evidence of the superiority of the RC system over the WO system.

On SEM, surface cracking was only seen in WO instruments [Figure 3]. It should be stressed that although these cracks were already apparent after the first instrument use, the files remained fracture resistant and could be reused at least five times before separation.

\section{DISCUSSION}

Major changes in the techniques and principles of endodontics have occurred in the last 20 years. ${ }^{[2]}$ This is demonstrated clearly by recent advances in instrumentation of root canal systems, such as the development of safer techniques, ${ }^{[8]}$ files made from more elastic and stable alloys, ${ }^{[6]}$ and a lower rate of errors during endodontic instrumentation. ${ }^{[7]}$

The present study assessed the fracture strength and development of plastic deformations and/or surface cracks on RC R25 and WO primary reciprocating instruments, with and without cervical preflaring, by means of operating microscope and SEM images. The null hypothesis of the study was rejected as the results demonstrated that cervical preflaring had an impact on the fracture strength of the tested instruments.

The choice of instruments for this study was based on the fact that both were made from the same material (NiTi $\mathrm{M}$-Wire alloy), are driven by reciprocating motion, and share similar manufacturing processes..$^{[1]}$

The method of reusing sterilized instruments on extracted human teeth simulates a real-world clinical

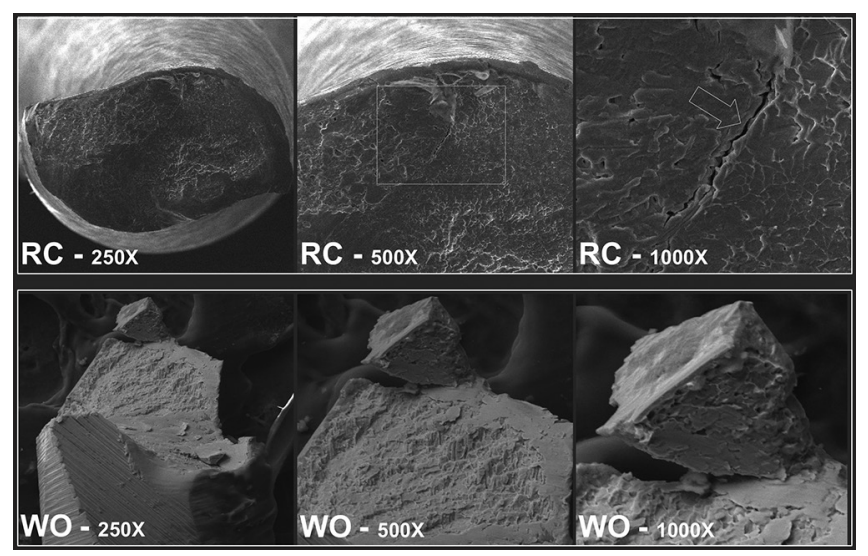

Figure 4: Reciproc $^{\circledR}$ (used in 12 teeth - GI) and WaveOne ${ }^{\circledR}$ (used in 6 teeth - GII) instruments after separation (scanning electron microscope images magnification: $\times 250, \times 500, \times 1000)$. Note cracks inside the metal mass of Reciproc ${ }^{\circledR}$ (arrow)

setting, particularly in terms of the risk of instrument separation, although not all anatomical features of the pulp cavity can be standardized. ${ }^{[5]}$ However, the large sample size, random allocation of teeth across study groups, and glidepath standardization with a \#13 PathFile prevented this variable from having any significant influence on results.

Negotiating the apical foramen and determining apical patency with \#15 or smaller files are essential clinical steps and are firmly enshrined in current practice as they prevent plugging and/or deviation of the root canal. ${ }^{[12]}$ Hence, the inclusion of these steps in our methods brings our experiment even closer to the reality of daily clinical practice as clearance of potential interferents from the root canal system and determination of apical patency play a critical role in ensuring safety and improving the prognosis of endodontic treatment. ${ }^{[13]}$

Likewise, the use of cervical preflaring - a clinical procedure widely employed in endodontic practice - in Groups G2 and G4 of this study further demonstrates our concern with making our experimental condition reproduce clinical aspects as closely as possible. Preflaring ensures there is a sufficient space for penetration of the mechanical instrument, prevents coronal binding, and reduces the risk of instrument separation. ${ }^{[7]}$ In addition, it enhances the range of action of irrigating solution by enabling advancement of the irrigation needle and penetration of the ultrasonic tip during passive ultrasonic irrigation (PUI). ${ }^{[5]}$

Although the RC and WO instruments were conceived for single use only, these devices have a high level 
of embedded technology, which led us to analyze their fracture strength after repeated sterilization before each reuse. This analysis showed that both instruments remained safe for reuse.

According to the current literature, the advent of reciprocating motion systems has made root canal shaping and cleaning safer. ${ }^{[8]}$ Several studies have shown that reciprocation provides increased cyclic fatigue resistance for NiTi instruments. ${ }^{[14,15]}$ In addition, the past studies suggest the possibility of using only one instrument to prepare the entire root canal with satisfactory results, particularly because a single instrument has increased fracture strength as compared to full-sequence rotary instrumentation. ${ }^{[14,16]}$

The influence of cross-section, alloy type, manufacturing process, and type of driving motion on the cyclic fatigue resistance of NiTi instruments has been the object of several recent studies. ${ }^{[15,17]}$ Nevertheless, how and why the design of the instrument might influence its behavior under cyclic fatigue stress remains unclear. Cheung and Darvell ${ }^{[18]}$ showed, in various instruments, that fatigue resistance does not appear to be affected by instrument design, suggesting that neither the cross-section area of an instrument nor its shape is the primary determinant of fatigue life.

However, other studies have suggested that difference in cross-section appears to be an important determinant of cyclic fatigue resistance across different files. ${ }^{[19]}$ In a study conducted by Plotino et al., ${ }^{[20]} \mathrm{RC}$ instruments exhibited significantly greater fatigue strength than WO instruments, which suggests that this difference may be related to the differences in cross-sectional area and reciprocating motion between the two systems. Earlier studies also demonstrated the superiority of RC instrumentation over the WO system in fatigue resistance testing ${ }^{[21]}$ and have shown that the angles employed in instrument motion have a direct influence on cyclic fatigue. ${ }^{[22]}$ Kiefner et al..$^{[14]}$ believe another factor that enhances resistance in RC and WO instruments is the type of alloy used in their manufacture. The authors showed that a synergistic effect between the M-Wire alloy and reciprocating motion provides a significant increase in cyclic fatigue resistance. Recently, a new continuous rotary instrument was developed by Coltene/Whaledent AG (Hyflex EDM). Manufactured using the electrical discharge machining technique, this instrument has greater resistance to cyclic fatigue when compared with RC and WO.
In our sample, the RC system was superior to the WO system regardless of cervical preflaring, which suggests that clearance of the root canal system through glidepath preparation before instrumentation is of the utmost clinical importance. ${ }^{[23]}$ This step is recommended by the manufacturer of WO but deemed unnecessary when using the RC system. ${ }^{[24]}$ Perhaps, choosing not to prepare a glidepath could bias results significantly in favor of the RC system as demonstrated elsewhere in the literature. ${ }^{[20]}$

In a study of discarded NiTi files, Alapati et al. ${ }^{[3]}$ found cracks along the metal body of the instruments. In our sample, SEM analysis of the instruments after the first use revealed cracks only on the WO files. We did not observe any plastic deformation, which may be explained by the greater resistance of the M-Wire alloy as compared with other NiTi alloys. ${ }^{[17]}$

It bears stressing that the back-and-forth motion recommended by manufacturers and followed during specimen preparation in this study is largely intended to reduce torsional strain and, consequently, torsion fatigue, whereas its effect on flexural stresses is probably less evident. To date, $\mathrm{RC}$ and WO have been marketed for single-file root canal instrumentation and are approved for single use only so as to prevent structural weakening as a result of cyclic fatigue. However, "single use" means the same instrument may still be used to instrument three or four root canals, each of which may have complex, tortuous anatomy. ${ }^{[1]}$ Therefore, single use reduces but does not altogether eliminate the risk of cumulative fatigue damage and potential instrument separation. Hence, we conclude that cyclic fatigue testing is as valuable for reciprocating instrumentation as for rotary instruments.

It should be noted that the high level of fatigue resistance of reciprocating instruments may play an important role in improving root canal cleaning and shaping procedures as shaping can be done with remarkable speed. Within this context, the principles of endodontics are shifting away from simultaneous cleaning and shaping toward a paradigm, whereby the root canal system is first shaped to enable effective cleaning by means of enhanced irrigation procedures. ${ }^{[25]}$ Evidence suggests that enhanced apical preparation provides a greater reduction of bacterial load and dentin debris, primarily by enabling more effective irrigation, ${ }^{[4]}$ which is made easier by cervical preparation. ${ }^{[26]}$ 
In the present study, cervical preflaring before instrumentation played a relevant role in increasing the fatigue life of the tested instruments. Another relevant clinical factor is localization, negotiation, and determination of apical patency, especially as endodontic treatment of older adults - who often present with constricted pulp chambers filled with dystrophic calcifications - has become more common. Therefore, canal clearance and apical debridement are considered important procedures to reduce instrument stress against the walls of the canal system and thus improve the safety of endodontic treatment. ${ }^{[6]}$ Nevertheless, in a recent study by De-Deus et al., ${ }^{[24]}$ the $\mathrm{RC}$ system demonstrated satisfactory fracture strength even in the absence of patent canals.

The present study sought to assess the fracture strength of $\mathrm{RC}$ and $\mathrm{WO}$ instruments after repeated sterilization and reuse cycles. Our results suggest

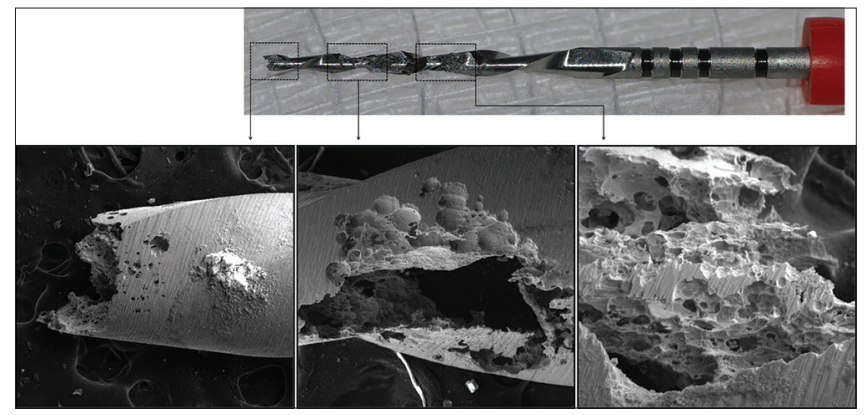

Figure 5: Scanning electron microscope images $(\times 100)$ of a Reciproc ${ }^{\circledast}$ R25 instrument showing corrosion and loss of metal mass that both the RC and WO systems can be safely reused several times, preceded by some preliminary manipulation to prevent the instrument from binding and thus reduce the risk of separation. Based on our findings, we suggest that files can be reused safely up to 3 times. This number also facilitates control of the number of reuses of a single file. On the first use, the instrument is taken directly from its original packaging and its identifier ring is intact. After the first reprocessing, the identifier ring is enlarged and must be removed before the instrument can fit into the handpiece; this serves as a milestone for the second use of the instrument. Finally, at the time of the third use, the instrument will already be missing its identifier ring, which demonstrates it should be discarded after use.

Despite these conclusions, we believe that further research is needed to assess the ability of these reciprocating systems to ensure adequate canal antisepsis, as the duration of exposure to $\mathrm{NaOCl}$ irrigating solution tends to be reduced in single-file preparations, and to evaluate the influence of this clinical practice on treatment success over time.

Notably, one of the instrument specimens produced dark discoloration of the irrigation solution shortly after the start of its first use. The canal was irrigated with fresh solution and dark discoloration occurred again. Upon removal of the instrument from the root canal, it was found to have been markedly corroded

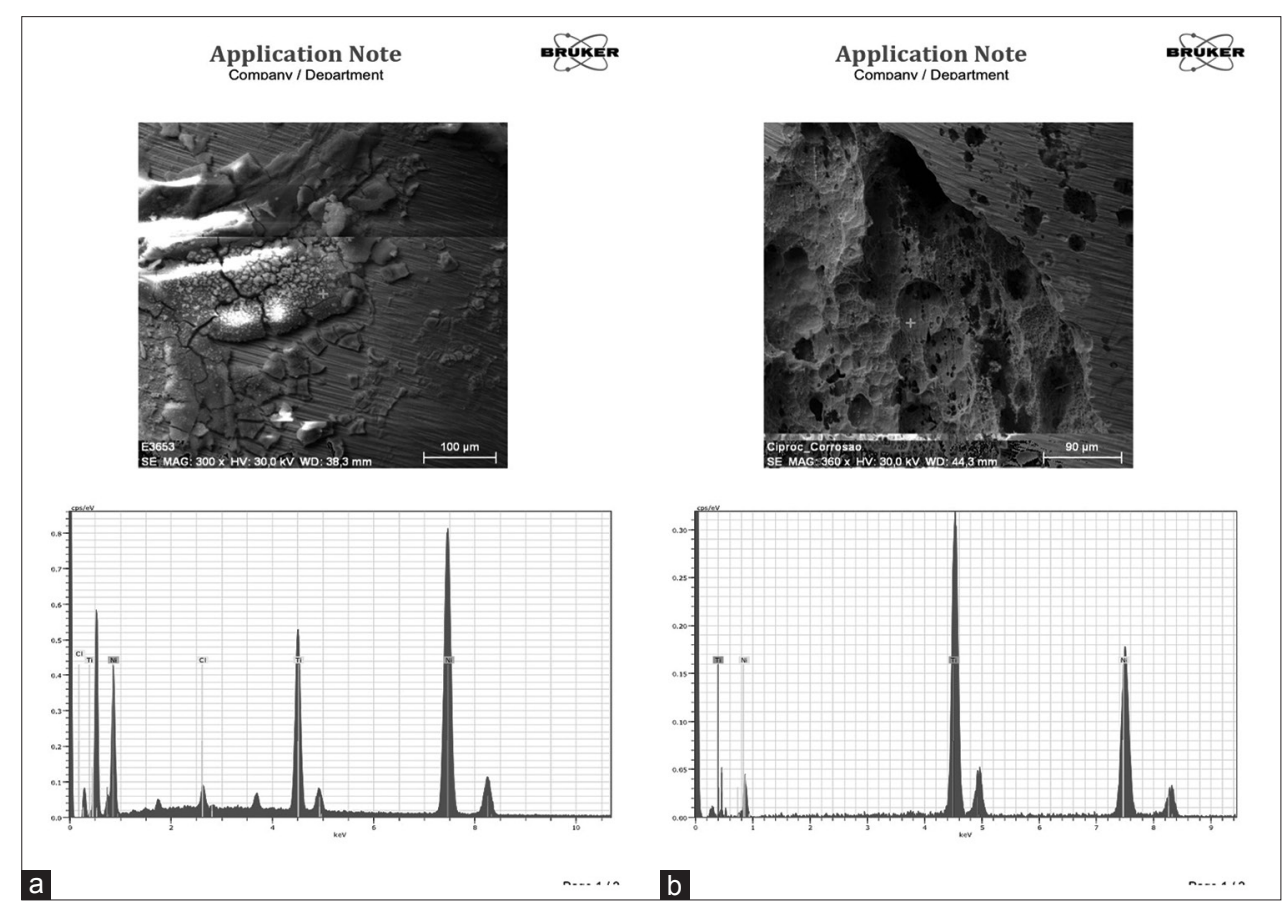

Figure 6: Energy dispersive X-ray analyses of the surface (a) and eroded area (b) of the instrument damaged by $2.5 \%$ sodium hypochlorite solution 
by the $2.5 \% \mathrm{NaOCl}$ solution, with loss of material. On SEM examination, this instrument (lot \#1108000846) exhibited structural changes [Figure 5]. Energy dispersive $X$-ray analysis did not show any difference in alloy properties in relation to the other instruments used in the study [Figure 6]. It bears stressing that no instances of such damage, i.e., structural corrosion of NiTi instruments by $\mathrm{NaOCl}$ solution, have ever been reported in the literature. ${ }^{[21]}$ This event was probably due to a flaw in the manufacturing process as other instruments from the same lot exhibited stable behavior.

\section{CONCLUSION}

Considering the proposed objective of this study, we conclude that both RC and WO instruments exhibited good fracture strength after autoclave sterilization and reuse. Cervical preflaring significantly increased the number of times RC and WO files could be reused safely.

\section{Financial support and sponsorship}

Nil.

\section{Conflicts of interest}

There are no conflicts of interest.

\section{REFERENCES}

1. Magalhães RR, Braga LC, Pereira ÉS, Peixoto IF, Buono VT, Bahia MG. The impact of clinical use on the torsional behavior of Reciproc and WaveOne instruments. J Appl Oral Sci 2016;24:310-6.

2. Plotino G, Ahmed HM, Grande NM, Cohen S, Bukiet F. Current assessment of reciprocation in endodontic preparation: A comprehensive review - Part I: Properties and effectiveness. J Endod 2015;41:1939-50.

3. Alapati SB, Brantley WA, Svec TA, Powers JM, Nusstein JM, Daehn GS. SEM observations of nickel-titanium rotary endodontic instruments that fractured during clinical Use. J Endod 2005;31:40-3.

4. Al-Sudani D, Grande NM, Plotino G, Pompa G, Di Carlo S, Testarelli L, et al. Cyclic fatigue of nickel-titanium rotary instruments in a double (S-shaped) simulated curvature. J Endod 2012;38:987-9.

5. Yao JH, Schwartz SA, Beeson TJ. Cyclic fatigue of three types of rotary nickel-titanium files in a dynamic model. J Endod 2006;32:55-7.

6. Berutti E, Chiandussi G, Paolino DS, Scotti N, Cantatore G, Castellucci A, et al. Canal shaping with WaveOne Primary reciprocating files and ProTaper system: A comparative study. J Endod 2012;38:505-9.

7. Ehrhardt IC, Zuolo ML, Cunha RS, De Martin AS, Kherlakian D,
Carvalho MC, et al. Assessment of the separation incidence of mtwo files used with preflaring: Prospective clinical study. J Endod 2012;38:1078-81.

8. Yared G. Canal preparation using only one Ni-Ti rotary instrument: Preliminary observations. Int Endod J 2008;41:339-44.

9. Grande NM, Ahmed HM, Cohen S, Bukiet F, Plotino G. Current assessment of reciprocation in endodontic preparation: A comprehensive review-part I: Historic perspectives and current applications. J Endod 2015;41:1778-83.

10. Hanan AR, Meireles DA, Sponchiado Júnior EC, Hanan S, Kuga MC, Bonetti Filho I. Surface characteristics of reciprocating instruments before and after use - a SEM analysis. Braz Dent J 2015;26:121-7.

11. Plotino G, Giansiracusa Rubini A, Grande NM, Testarelli L, Gambarini G. Cutting efficiency of Reciproc and waveOne reciprocating instruments. J Endod 2014;40:1228-30.

12. Estrela C, Holland R, Estrela CR, Alencar AH, Sousa-Neto MD, Pécora JD. Characterization of successful root canal treatment. Braz Dent J 2014;25:3-11.

13. West JD. The endodontic Glidepath: "Secret to rotary safety". Dent Today 2010;29:86, 88, 90-3

14. Kiefner P, Ban M, De-Deus G. Is the reciprocating movement per se able to improve the cyclic fatigue resistance of instruments? Int Endod J 2014;47:430-6.

15. Pedullà E, Lo Savio F, Boninelli S, Plotino G, Grande NM, La Rosa G, et al. Torsional and cyclic fatigue resistance of a new nickel-titanium instrument manufactured by electrical discharge machining. J Endod 2016;42:156-9.

16. Franco V, Fabiani C, Taschieri S, Malentacca A, Bortolin M, Del Fabbro M. Investigation on the shaping ability of nickel-titanium files when used with a reciprocating motion. J Endod 2011;37:1398-401.

17. Ye J, Gao Y. Metallurgical characterization of M-Wire nickel-titanium shape memory alloy used for endodontic rotary instruments during low-cycle fatigue. J Endod 2012;38:105-7.

18. Cheung GS, Darvell BW. Low-cycle fatigue of NiTi rotary instruments of various cross-sectional shapes. Int Endod J 2007;40:626-32.

19. Zhang EW, Cheung GS, Zheng YF. Influence of cross-sectional design and dimension on mechanical behavior of nickel-titanium instruments under torsion and bending: A numerical analysis. J Endod 2010;36:1394-8

20. Plotino G, Grande NM, Testarelli L, Gambarini G. Cyclic fatigue of Reciproc and WaveOne reciprocating instruments. Int Endod J 2012;45:614-8.

21. Pedullà E, Franciosi G, Ounsi HF, Tricarico M, Rapisarda E, Grandini S. Cyclic fatigue resistance of nickel-titanium instruments after immersion in irrigant solutions with or without surfactants. J Endod 2014;40:1245-9

22. Higuera O, Plotino G, Tocci L, Carrillo G, Gambarini G, Jaramillo DE. Cyclic fatigue resistance of 3 different nickel-titanium reciprocating instruments in artificial canals. J Endod 2015:41:913-5.

23. Berutti E, Paolino DS, Chiandussi G, Alovisi M, Cantatore G, Castellucci A, et al. Root canal anatomy preservation of WaveOne reciprocating files with or without glide path. J Endod 2012;38:101-4

24. De-Deus G, Arruda TE, Souza EM, Neves A, Magalhães K, Thuanne E, et al. The ability of the Reciproc R25 instrument to reach the full root canal working length without a glide path. Int Endod J 2013;46:993-8.

25. Schmidt TF, Teixeira CS, Felippe MC, Felippe WT, Pashley DH, Bortoluzzi EA. Effect of ultrasonic activation of irrigants on smear layer removal. J Endod 2015;41:1359-63.

26. Neves MA, Provenzano JC, Rôças IN, Siqueira JF Jr. Clinical antibacterial effectiveness of root canal preparation with reciprocating single-instrument or continuously rotating multi-instrument systems. J Endod 2016;42:25-9. 